\title{
Avaliação de cultivares de soja, sob manejo orgânico, para fins de adubação verde e produção de grãos ${ }^{(1)}$
}

\author{
Milton Parron Padovan ${ }^{(2)}$, Dejair Lopes de Almeida ${ }^{(3)}$, José Guilherme Marinho Guerra ${ }^{(3)}$, \\ Raul de Lucena Duarte Ribeiro(4) e Aly Ndiaye ${ }^{(5)}$
}

\begin{abstract}
Resumo - O objetivo deste trabalho foi avaliar o desempenho de seis cultivares de soja, sob manejo orgânico, para fins de adubação verde e produção de grãos. Utilizou-se delineamento experimental de blocos casualizados, com quatro repetições por tratamento (cultivar). Na época da colheita, 81 dias após a emergência das plântulas, todas as cultivares testadas (Celeste, Surubi, Campo Grande, Mandi, Lambari e Taquari) mostraram excelente nodulação, variando de 545 a $760 \mathrm{mg} /$ planta de massa nodular seca. As cultivares Celeste e Taquari, que produziram, respectivamente, 8,33 e 7,12 tha ${ }^{-1}$ de biomassa seca da parte aérea, apresentaram outras características agronômicas vantajosas, tais como: ciclo curto, alta acumulação de nutrientes (N, P, K, Ca e $\mathrm{Mg}$ ) nos tecidos verdes e bom rendimento de sementes. Esses caracteres indicam potencial de 'Celeste' e 'Taquari' para adubação verde de verão em sistemas de agricultura orgânica. Cinco das cultivares avaliadas revelaram tendência ao acamamento, porém dentro de níveis aceitáveis. As cultivares Celeste, Surubi, Campo Grande, Mandi e Taquari suplantaram em $23 \%, 32 \%, 33 \%, 44 \%$ e $70 \%$, respectivamente, a média nacional de produtividade de soja, estimada em $2.398 \mathrm{~kg} \mathrm{ha}^{-1}$ nas últimas três safras.
\end{abstract}

Termos para indexação: Glycine max, fixação de nitrogênio, ciclo biogeoquímico, desempenho de cultura.

\section{Evaluation of soybean cultivars under organic management for green manuring and grain production}

\begin{abstract}
The objective of this work was to evaluate the grain and aboveground biomass production of six soybean cultivars under organic management. A randomized block design was adopted with four replications per treatment (cultivar). By harvest time, 81 days after plants emergence, all tested cultivars (Celeste, Surubi, Campo Grande, Mandi, Lambari, and Taquari) had excellent nodulation ranging from 545 to $760 \mathrm{mg} /$ plant of nodule mass (dry weight). The cultivars Celeste and Taquari, which yielded 8.33 and $7.12 \mathrm{tha}^{-1}$ of dry biomass, respectively, showed other advantageous agronomic characteristics such as: short cycle, a high accumulation of nutrients $(\mathrm{N}, \mathrm{P}, \mathrm{K}, \mathrm{Ca}$ and $\mathrm{Mg}$ ) in green tissues, and good seed setting. These traits indicated potential of 'Celeste' and 'Taquari' to be used as green manure summer crops in organic agriculture systems. Five of the cultivars revealed a tendency for lodging, however within acceptable levels. Cultivars Celeste, Surubi, Campo Grande, Mandi, and Taquari exceeded in $23 \%, 32 \%, 33 \%, 44 \%$, and $70 \%$, respectively, the Brazilian soybean grain yield average of 2,398 kg ha-1 of the last three years.
\end{abstract}

Index terms: Glycine max, nitrogen fixation, cycling, crop performance.

(1) Aceito para publicação em 9 de agosto de 2002.

Trabalho integrante das Redes Cooperativas de Pesquisa do Estado do Rio de Janeiro, Projeto Rede Agroecologia Rio, com apoio da Faperj e Finep.

(2) Instituto de Desenvolvimento Agrário, Pesquisa, Assistência Técnica e Extensão Rural de Mato Grosso do Sul/Universidade Federal Rural do Rio de Janeiro (UFRRJ), Caixa Pos- tal 472, CEP 79031-902 Campo Grande, MS. E-mail: agroecology@bol.com.br

(3) Embrapa-Centro Nacional de Pesquisa de Agrobiologia (CNPAB), BR 465, km 7, CEP 23851-970 Seropédica, RJ. E-mail:dejair@cnpab.embrapa.br, gmguerra@cnpab.embrapa.br (4) UFRRJ, Dep. de Entomologia e Fitopatologia, BR 465, km 7, Seropédica, RJ. E-mail: lucena@ufrrj.br

${ }^{(5)}$ Embrapa-CNPAB/UFRRJ. Bolsista CNPq/Pibic. E-mail: aly@agrosuisse.com.br 


\section{Introdução}

O Brasil é o segundo produtor mundial de soja (Agrianual, 2000), com produtividade média, nos últimos três anos, de $2.398 \mathrm{~kg} \mathrm{ha}^{-1}$. Apesar de a soja ser considerada cultura de grandes produtores, o tamanho médio das áreas cultivadas no País é de 38,02 hectares (IBGE, 1998). Não há estatística oficial disponível para identificação do perfil da produção de soja em sistema orgânico no País.

A cultura da soja possui potencial para exercer múltiplas funções em sistemas de produção. Além de gerar produto de elevado valor biológico, como o alto teor de proteína dos grãos, cerca de $40 \%$ (Hungria et al., 1994), apresenta capacidade de fixar biologicamente elevadas quantidades de nitrogênio.

No Brasil, Franco et al. (1978) estimaram que a fixação biológica de $\mathrm{N}$ (FBN) da soja varia de 40 a $206 \mathrm{~kg} \mathrm{ha}^{-1}$; Boddey et al. $(1984 ; 1990)$ encontraram taxas de FBN de 109 a $250 \mathrm{~kg} \mathrm{ha}^{-1}$ e Zotarelli (2000) de até $294 \mathrm{~kg} \mathrm{ha}^{-1}$, comparativamente ao amendoim (Arachis hypogaea), de 72 a $124 \mathrm{~kg} \mathrm{ha}^{-1}$, ao grão-de-bico (Cicer arietinum), de 50 a $103 \mathrm{~kg} \mathrm{ha}^{-1}$, ao feijão (Phaseolus vulgaris), de 2,7 a $110 \mathrm{~kg} \mathrm{ha}^{-1}$, e à ervilha (Pisum sativum), de 52 a $77 \mathrm{~kg} \mathrm{ha}^{-1}$ (Siqueira $\&$ Franco, 1988).

A soja apresenta potencial para cultivo consorciado com o milho, objetivando a melhoria do rendimento e do valor nutritivo da forragem (Obeid et al., 1985; Oliveira et al., 1988; Lempp et al., 2000), e em sistemas de produção envolvendo rotações de culturas, com expressivos resultados (Santos et al., 1998; Fontaneli et al., 2000).

Em virtude do alto vigor e da boa produção de fitomassa por diversas cultivares, a soja constitui boa alternativa como adubo verde, notadamente em sistemas orgânicos de cultivo, prioritariamente em solos mais férteis. Nas últimas décadas, verifica-se escassez de dados relativos a essa leguminosa quanto à acumulação de biomassa, teor e acumulação de nutrientes na parte aérea, pois apesar de ser uma cultura de caráter multifuncional, talvez a única com atributos tão elevados, a pesquisa tem negligenciado seu potencial como adubo verde, considerando sua ampla adaptabilidade à heterogênea condição edafoclimática do território brasileiro, o que é restrito na maioria das espécies atualmente utilizadas ou difundidas como adubo verde.
A manutenção e a melhoria das reservas de $\mathrm{N}$ no solo, bem como o seu suprimento às plantas cultivadas, representam grandes desafios da agricultura orgânica (Altieri, 1989). Em trabalhos realizados em sistemas orgânicos, certos estercos têm sido utilizados como fonte de nutrientes para as plantas, principalmente o bovino e a cama de aviário. Entretanto, estudos demonstraram a necessidade de utilização de grandes quantidades desses materiais (Almeida, 1991; Oliveira, 2001), o que limita sua aplicação em virtude do reduzido número de criações conduzidas de acordo com os preceitos da produção orgânica. Com o novo panorama, o cultivo da soja como adubo verde, especialmente em sistemas de produção de alta rotatividade de culturas, pode representar importante fonte de $\mathrm{N}$ fixada biologicamente a ser aportada aos sistemas de produção.

O objetivo deste trabalho foi avaliar o desempenho de cultivares de soja, sob manejo orgânico, para fins de adubação verde e produção de grãos.

\section{Material e Métodos}

O trabalho foi realizado no ano agrícola 1999/2000, no Sistema Integrado de Produção Agroecológica - Fazendinha Agroecológica (Sipa), onde todo o manejo segue os preceitos da agricultura orgânica, conduzida desde 1993 mediante parceria entre Embrapa-Centro Nacional de Pesquisa de Agrobiologia, Embrapa-Centro Nacional de Pesquisa de Solos, Universidade Federal Rural do Rio de Janeiro (UFRRJ) e Empresa de Pesquisa Agropecuária do Estado do Rio de Janeiro (Pesagro), em Seropédica, no Estado do Rio de Janeiro. É situada a $22^{\circ} 46^{\prime} \mathrm{S}$ e $43^{\circ} 41^{\prime} \mathrm{O}$, e a $33 \mathrm{~m}$ de altitude (Almeida et al., 1999). O solo é classificado como Argissolo Vermelho-Amarelo (Embrapa, 1999), cujo resultado das análises químicas de amostra superficial $(0-20 \mathrm{~cm})$ apresentou $\mathrm{pH}$ em água 6,$0 ; \mathrm{Al}^{+3}$, $0,0 \mathrm{cmol}_{\mathrm{c}} \mathrm{dm}^{-3} ; \quad \mathrm{Ca}^{+2}, \quad 3,6 \mathrm{cmol}_{\mathrm{c}} \mathrm{dm}^{-3} ; \mathrm{Mg}^{+2}$, $1,9 \mathrm{cmol}_{\mathrm{c}} \mathrm{dm}^{-3} ; \mathrm{P}, 50 \mathrm{mg} \mathrm{dm}^{-3}$; $\mathrm{e} \mathrm{K}^{+}, 54 \mathrm{mg} \mathrm{dm}^{-3}$. Os tratamentos foram compostos por seis cultivares de soja: Celeste, Campo Grande, Surubi, Mandi, Lambari e Taquari, identificadas como apropriadas para o cultivo no Estado do Rio de Janeiro. O delineamento experimental adotado foi o de blocos ao acaso, com quatro repetições. As parcelas foram constituídas por quatro fileiras de $7 \mathrm{~m}$ de comprimento, espaçadas em $0,5 \mathrm{~m}$ entre as linhas, e utilizou-se uma densidade de semeadura de 15 a 20 sementes por metro linear. A área útil para amostragem foi representada pelas duas fileiras centrais, desprezando-se $0,5 \mathrm{~m}$ de cada extremidade. 
O solo foi preparado por meio de aração e gradagem leve e recebeu $1,0 \mathrm{tha}^{-1}$ da mistura de termofosfato magnesiano com cinzas de madeira, na proporção de 1:1 (peso/peso), como fontes de $\mathrm{P}, \mathrm{K}, \mathrm{Ca}, \mathrm{Mg}, \mathrm{B}, \mathrm{Mo}, \mathrm{Zn}$, Mn e cobre.

Bactérias do gênero Bradyrhizobium, específicas para a cultura, foram inoculadas nas sementes. O plantio foi realizado no dia 1/12/1999.

O controle de plantas invasoras foi realizado por meio de capina manual, efetuada 20 dias após a emergência da soja. A ocorrência de insetos pragas e doenças foi monitorada mediante amostragens realizadas a cada 10 dias, a partir do estádio de desenvolvimento $\mathrm{V}_{4}$ a $\mathrm{V}_{5}$ até $\mathrm{R}_{7}$ (Fehr \& Caviness, 1977), constatando-se níveis muito baixos, não necessitando de utilização de qualquer intervenção para o controle.

A nodulação foi avaliada em cinco plantas de cada parcela, por meio de lavagem e contagem dos nódulos do sistema radicular; posteriormente os nódulos foram secados em estufa de ventilação forçada a $65^{\circ} \mathrm{C}$, até massa constante.

A biomassa e os nutrientes acumulados na parte aérea da soja foram avaliados na fase de formação de vagens, compreendendo o estádio de desenvolvimento $\mathrm{R}_{4}$ (Fehr \& Caviness, 1977), entre 20 e 33 dias após o início do florescimento. $\mathrm{O}$ material vegetal contido em $1 \mathrm{~m}^{2} \mathrm{da}$ área útil das parcelas foi cortado rente ao solo e pesado para determinação da massa fresca. Desse material, cinco plantas foram separadas e secadas em estufa de ventilação forçada a $65^{\circ} \mathrm{C}$, até peso constante, para determinação da massa seca e da acumulação de N, P, K, Ca e Mg pela planta.

O ciclo de maturação foi avaliado quando $95 \%$ das vagens alcançaram a maturação, apresentando a coloração típica da cultivar (estádio $\mathrm{R}_{8}$ ). A altura média das plantas foi determinada a partir da superfície do solo até a extremidade do caule principal, na época da maturação, e a altura média de inserção das primeiras vagens foi determinada a partir da superfície do solo.

O acamamento foi avaliado por ocasião da colheita, utilizando-se uma escala de 1 a 5 , em que 1: quase todas as plantas são eretas, 2: todas as plantas são levemente inclinadas ou até $25 \%$ das plantas são acamadas, 3: todas as plantas são inclinadas ou até $25 \%$ das plantas são acamadas, 4: todas as plantas são severamente inclinadas ou $50 \%$ a $80 \%$ das plantas são acamadas e 5: mais de $80 \%$ das plantas são acamadas.
A produção de grãos foi determinada mediante a colheita em $4 \mathrm{~m}^{2}$ da área útil de cada parcela, com o resultado em $\mathrm{t} \mathrm{ha}^{-1}$ de grãos a $13 \%$ de umidade.

Os resultados foram submetidos à análise de variância e as médias comparadas pelo teste de Tukey a 5\% de probabilidade.

\section{Resultados e Discussão}

Aos 43 dias após a emergência (DAE), a cultivar Campo Grande apresentou maior número de nódulos do que a Surubi, porém não diferiu das demais cultivares, que também apresentaram boa nodulação, com nódulos grandes (Tabela 1).

Aos 81 DAE, ocasião em que as cultivares encontravam-se na fase de formação de vagens, correspondendo ao estádio de desenvolvimento $\mathrm{R}_{4}$ (Fehr \& Caviness, 1977), observou-se acentuado aumento da nodulação em todas as cultivares, sem diferenças significativas entre elas. As cultivares apresentaram elevada nodulação (de 60 a 86 nódulos por planta), semelhante àquela obtida por Brose (1978), porém muito superior quanto à massa nodular, alcançando até $760 \mathrm{mg}$ por planta. Segundo Vargas et al. (1982), uma planta de soja bem nodulada deve mostrar, no campo, no estádio de florescimento, entre 15 a 30 nódulos ou 100 a 200 mg de massa nodular por planta.

Como a fixação de $\mathrm{N}_{2}$ está estreitamente relacionada à massa nodular (Döbereiner et al., 1966), a elevada nodulação alcançada pelas cultivares de soja neste estudo confirma o bom desempenho dos genótipos em relação à FBN.

Tabela 1. Nodulação de cultivares de soja, sob manejo orgânico, aos 43 e 81 dias após a emergência (DAE). Médias de quatro repetições ${ }^{(1)}$.

\begin{tabular}{lccccc}
\hline Cultivar & \multicolumn{2}{c}{$\begin{array}{c}\text { No de nódulos } \\
\text { planta }^{-1}\end{array}$} & & \multicolumn{2}{c}{$\begin{array}{c}\text { Massa nodular } \\
\left(\mathrm{mg} \mathrm{planta}^{-1}\right)\end{array}$} \\
\cline { 2 - 3 } \cline { 5 - 6 } & $43 \mathrm{DAE}$ & $81 \mathrm{DAE}$ & & $43 \mathrm{DAE}$ & $81 \mathrm{DAE}$ \\
\hline Taquari & $9 \mathrm{AB}$ & $62 \mathrm{~A}$ & & $58 \mathrm{~A}$ & $545 \mathrm{~A}$ \\
Mandi & $24 \mathrm{AB}$ & $72 \mathrm{~A}$ & & $114 \mathrm{~A}$ & $610 \mathrm{~A}$ \\
Campo Grande & $44 \mathrm{~A}$ & $87 \mathrm{~A}$ & & $112 \mathrm{~A}$ & $655 \mathrm{~A}$ \\
Surubi & $5 \mathrm{~B}$ & $72 \mathrm{~A}$ & & $37 \mathrm{~A}$ & $705 \mathrm{~A}$ \\
Celeste & $18 \mathrm{AB}$ & $67 \mathrm{~A}$ & & $97 \mathrm{~A}$ & $660 \mathrm{~A}$ \\
Lambari & $13 \mathrm{AB}$ & $60 \mathrm{~A}$ & & $88 \mathrm{~A}$ & $760 \mathrm{~A}$ \\
\hline CV $(\%)$ & 81,05 & 19,08 & & 67,07 & 17,07 \\
\hline${ }^{(1)}$ Em cada coluna, médias seguidas pela mesma letra não diferem entre si \\
pelo teste de Tukey a 5\% de probabilidade.
\end{tabular}

Pesq. agropec. bras., Brasília, v. 37, n. 12, p. 1705-1710, dez. 2002 
Utilizando-se como parâmetro a cultura da soja avaliada sob manejo convencional em diferentes regiões, os resultados alcançados pelas cultivares Celeste e Taquari no presente trabalho demonstram acumulação de N, P, K, Ca e Mg superior às obtidas por Bataglia et al. (1976) e Bataglia \& Mascarenhas (1977). Comparando com os resultados de Henderson \& Kamprath (1970), essas cultivares também apresentaram valores superiores de $\mathrm{P}, \mathrm{Ca}$, e $\mathrm{Mg}$, e Celeste apresentou maior acumulação de N; já os valores de K comparados foram similares (Tabela 2).

Em relação a outros sistemas de produção sob manejo orgânico, as cultivares Celeste e Taquari apresentaram acumulação de $\mathrm{N}$ semelhante à do feijão-de-porco (Canavalia ensiformis) e superior à da mucuna-preta (Mucuna aterrima), à do feijão-guandu (Cajanus cajan) (Souza, 1997) e à da crotalária (Crotalaria juncea) (Souza, 1997; Oliveira, 2001). Quanto à acumulação de $\mathrm{P}, \mathrm{K}, \mathrm{Ca}$ e Mg, essas cultivares de soja foram superiores ao

Tabela 2. Acumulação total de nutrientes na parte aérea de cultivares de soja aos 81 dias após a emergência (estádio de formação de vagens), sob manejo orgânico. Médias de quatro repetições ${ }^{(1)}$.

\begin{tabular}{llllll}
\hline Cultivar & $\mathrm{N}$ & $\mathrm{P}$ & $\mathrm{K}$ & $\mathrm{Ca}$ & $\mathrm{Mg}$ \\
& - & & \\
& $168 \mathrm{AB}$ & $20 \mathrm{AB}$ & $86 \mathrm{AB}$ & $85 \mathrm{AB}$ & $48 \mathrm{~A}$ \\
\hline Taquari & $147 \mathrm{~B}$ & $21 \mathrm{AB}$ & $79 \mathrm{AB}$ & $66 \mathrm{~B}$ & $35 \mathrm{AB}$ \\
Mandi & $144 \mathrm{~B}$ & $20 \mathrm{AB}$ & $76 \mathrm{AB}$ & $75 \mathrm{AB}$ & $34 \mathrm{AB}$ \\
Campo Grande & $113 \mathrm{~B}$ & $15 \mathrm{~B}$ & $63 \mathrm{~B}$ & $60 \mathrm{~B}$ & $29 \mathrm{~B}$ \\
Surubi & $223 \mathrm{~A}$ & $28 \mathrm{~A}$ & $112 \mathrm{~A}$ & $103 \mathrm{~A}$ & $51 \mathrm{~A}$ \\
Celeste & $132 \mathrm{~B}$ & $18 \mathrm{AB}$ & $74 \mathrm{AB}$ & $80 \mathrm{AB}$ & $36 \mathrm{AB}$ \\
Lambari & 18,98 & 28,31 & 22,99 & 16,74 & 19,85 \\
\hline CV $(\%)$ & & & & &
\end{tabular}

(1)Em cada coluna, médias seguidas pela mesma letra não diferem entre si pelo teste de Tukey a $5 \%$ de probabilidade. feijão-de-porco, mucuna-preta e feijão-guandu (Souza, 1997), e à crotalária (Souza, 1997; Oliveira, 2001).

A elevada produção de biomassa das cultivares Celeste e Taquari cultivadas sob manejo orgânico, aliada à precocidade, corroborado por resultados obtidos com outras cultivares de soja em diferentes ecorregiões (Henderson \& Kamprath, 1970; Hanway \& Weber, 1971a, 1971b; Egli \& Leggett, 1973; Bataglia et al., 1976; Bataglia \& Mascarenhas,1977), indica boas perspectivas para utilização da soja como adubo verde em sistemas de produção diversificados, com alta rotatividade de culturas, mediante plantios no verão (Tabela 3 ).

Os resultados com espécies utilizadas como adubos verdes em sistemas de produção com manejo orgânico, verificados por Souza (1997), em estudos com feijão-de-porco, mucuna-preta, crotalária e guandu; por Araújo \& Almeida (2000), ao avaliar a crotalária cultivada em consórcio com milho; e por Oliveira (2001), em experimentos com crotalária, demonstraram acumulação de biomassa inferior aos níveis alcançados pelas cultivares de soja Celeste e Taquari (8,33 e 7,12 $\mathrm{t} \mathrm{ha}^{-1}$, respectivamente), demonstrando o potencial de uso dessa leguminosa como adubo verde.

Outro aspecto favorável ao uso da soja na adubação verde consiste na facilidade para produção de sementes de boa qualidade, possibilitando aos agricultores a viabilização das quantidades necessárias nas próprias unidades de produção, garantindo sua independência em relação a esse insumo.

As avaliações relativas ao ciclo das cultivares, altura de plantas e inserção das primeiras vagens, acamamento e produção de grãos, foram realizadas

Tabela 3. Dados fitotécnicos de cultivares de soja sob manejo orgânico(1).

\begin{tabular}{|c|c|c|c|c|c|c|c|}
\hline Cultivar & $\begin{array}{l}\text { Floração } \\
\text { (dias) }\end{array}$ & $\begin{array}{l}\text { Biomassa seca } \\
\left(\mathrm{t} \mathrm{ha}^{-1}\right)^{(2)}\end{array}$ & $\begin{array}{r}\text { Ciclo } \\
\text { (dias) }\end{array}$ & $\begin{array}{c}\text { Altura } \\
\text { de plantas }(\mathrm{cm})\end{array}$ & $\begin{array}{c}\text { Altura } \\
\text { de inserção de } \\
\text { vagens }(\mathrm{cm})\end{array}$ & $\begin{array}{l}\text { Acamamento } \\
(1 \text { a } 5)^{(3)}\end{array}$ & $\begin{array}{c}\text { Produção } \\
\text { de grãos } \\
\left(\mathrm{t} \mathrm{ha}^{-1}\right)\end{array}$ \\
\hline Taquari & $50 \mathrm{D}$ & $7,12 \mathrm{AB}$ & $131 \mathrm{C}$ & $77 \mathrm{~A}$ & $14 \mathrm{~A}$ & $2,63 \mathrm{AB}$ & $4,07 \mathrm{~A}$ \\
\hline Mandi & $52 \mathrm{D}$ & $5,64 \mathrm{~B}$ & $132 \mathrm{C}$ & $77 \mathrm{~A}$ & $14 \mathrm{~A}$ & $2,75 \mathrm{~A}$ & $3,46 \mathrm{AB}$ \\
\hline Campo Grande & $53 \mathrm{C}$ & $5,43 \mathrm{~B}$ & $132 \mathrm{C}$ & $76 \mathrm{~A}$ & $14 \mathrm{~A}$ & $2,00 \mathrm{AB}$ & $3,19 \mathrm{~B}$ \\
\hline Surubi & $61 \mathrm{~A}$ & $4,59 \mathrm{~B}$ & $140 \mathrm{~A}$ & $79 \mathrm{~A}$ & $15 \mathrm{~A}$ & $1,75 \mathrm{AB}$ & $3,18 \mathrm{~B}$ \\
\hline Celeste & $57 \mathrm{~B}$ & $8,33 \mathrm{~A}$ & $135 \mathrm{~B}$ & $87 \mathrm{~A}$ & $15 \mathrm{~A}$ & $2,75 \mathrm{~A}$ & $2,94 \mathrm{~B}$ \\
\hline Lambari & $48 \mathrm{E}$ & $5,34 \mathrm{~B}$ & $120 \mathrm{D}$ & $57 \mathrm{~B}$ & 9B & $1,00 \mathrm{~B}$ & $1,66 \mathrm{C}$ \\
\hline $\mathrm{CV}(\%)$ & 1,06 & 18,83 & 0,59 & 8,36 & 7,70 & 34,54 & 11,07 \\
\hline
\end{tabular}

${ }^{(1)}$ Em cada coluna, médias seguidas pela mesma letra não diferem entre si pelo teste de Tukey a $5 \%$ de probabilidade. ${ }^{(2)}$ Valores médios de quatro repetições, aferidos aos 81 dias após a emergência. ${ }^{(3)} 1$ : $>90 \%$ de plantas eretas; 5 : $>80 \%$ de plantas acamadas. 
no estádio de desenvolvimento $\mathrm{R}_{8}$ (Fehr \& Caviness, 1977), correspondendo à maturação fisiológica (Tabela 3). Cinco das cultivares testadas demonstraram tendência ao acamamento, apresentando índices de 1,75 a 2,75 , baseado numa escala compreendida entre 1 (quase todas as plantas eretas) e 5 (mais de $80 \%$ das plantas acamadas), encontrando-se em níveis aceitáveis, porém com riscos de aumento de perdas no caso de eventual colheita mecânica, o que requer maiores cuidados na operação. As cultivares Celeste, Surubi, Campo Grande, Mandi e Taquari superaram a produtividade média nacional dos últimos três anos, estimada em $2.398 \mathrm{~kg} \mathrm{ha}^{-1}$ (Agrianual, 2000), em $23 \%, 32 \%, 33 \%, 44 \%$ e $70 \%$, respectivamente. Somente a cultivar Lambari apresentou limitação na arquitetura das plantas, com baixa altura de inserção das primeiras vagens, aumentando o risco de perda em caso de colheita mecanizada. Considerando que um dos principais preceitos da agricultura orgânica constitui-se na priorização do uso dos recursos internos da unidade de produção (Altieri, 1989; Paschoal, 1995; Almeida et al., 1999; Gliessman, 2000), as características de limitada altura de inserção das primeiras vagens e leve acamamento tornam-se desprezíveis, uma vez que privilegia-se nesse sistema de produção o aumento do uso da mão-de-obra familiar nas atividades rurais. Apesar dos elevados níveis de produtividade de grãos, as cultivares que mais se destacaram enquadram-se nos ciclos médio a tardio, sendo desejável a identificação de outras de ciclos mais precoces, de modo a aumentar as alternativas de rotação de culturas.

\section{Conclusões}

1. A cultura da soja possui atributos desejáveis para cultivo como adubo verde no período de verão, em sistemas de produção diversificados, manejados conforme os preceitos da agricultura orgânica.

2. Existem cultivares de soja que acumulam precocemente elevadas quantidades de biomassa e nutrientes.

3. As cultivares Taquari, Mandi, Campo Grande, Surubi e Celeste apresentam desempenho agronômico satisfatório, com elevados rendimentos de grãos, e são promissoras para cultivos submetidos a manejo orgânico.

\section{Referências}

AGRIANUAL 2001: anuário da agricultura brasileira. São Paulo: FNP Consultoria, 2000. 545 p.

ALMEIDA, D. L. Contribuição da adubação orgânica para a fertilidade do solo. 1991. 192 f. Tese (Doutorado em Ciência do Solo) - Universidade Federal Rural do Rio de Janeiro, Seropédica, 1991.

ALMEIDA, D. L.; RIBEIRO, R. de L. D.; GUERRA, J. G. M. Sistema integrado de produção agroecológica: "Fazendinha Agroecológica km 47". In: SIMPÓSIO DE AGRICULTURA ECOLÓGICA, 2.; ENCONTRO DE AGRICULTURA ORGÂNICA, 1999, São Paulo. Anais... Guaíba: Agropecuária, 1999. p. 153-159.

ALTIERI, M. A. Agroecologia: as bases científicas para a agricultura alternativa. Rio de Janeiro: Projeto e Tecnologias Alternativas/FASE, 1989. 240 p.

ARAÚJO, P. A. de; ALMEIDA, D. L. Produção de grãos de milho em sistema de cultivo consorciado com Crotalaria juncea em sistema orgânico de produção. Seropédica: Embrapa-CNPAB, 2000. 8 p.

Bataglia, O. C.; MASCAREnhas, H. A. A. Absorção de nutrientes pela soja. Campinas: Instituto Agronômico, 1977. 36 p. (Boletim Técnico, 41).

BATAGlia, O. C.; MASCARENHAS, H. A. A.; TEIXEIRA, J. P. F.; TISSELI FILHO, O. Acúmulo de matéria seca e nutrientes em soja, cultivar Santa Rosa. Bragantia, Campinas, v. 35, n. 21, p. 237-247, 1976.

BODDEY, R. M.; CHALK, P. M.; VICTORIA, R. L.; MATSUI, E. Nitrogen fixation by nodulated soybean under tropical field conditions estimated by the ${ }^{15} \mathrm{~N}$ isotope dilution technique. Soil Biology \& Biochemistry, Oxford, v. 16, n. 6 , p. 583-588, 1984.

BODDEY, R. M.; URQUIAGA, S.; NEVES, M. C. P. Quantification of the contribution of $\mathrm{N}_{2}$ fixation to field-grown grain legumes: a strategy for the practical application of ${ }^{15} \mathrm{~N}$ isotope dilution technique. Soil Biology \& Biochemistry, Oxford, v. 22, p. 649-655, 1990.

BROSE, E. Relação entre genótipos de soja (Glycine $\max ($ L.) Merrill), fixação simbiótica de nitrogênio e rendimento de grãos. 1978. 110 f. Dissertação (Mestrado em Agronomia) - Universidade Federal do Rio Grande do Sul, Porto Alegre, 1978. 
DÖBEREINER, J.; ARRUDA, N. B. de; PENTEADO, A. de F. Avaliação da fixação do nitrogênio, em leguminosas, pela regressão do nitrogênio total das plantas sobre o peso dos nódulos. Pesquisa Agropecuária Brasileira, Rio de Janeiro, v. 1, p. 233-237, 1966.

EGLI, D. B.; LEGGETT, J. E. Dry matter accumulation patterns in determinate and indeterminate soybeans. Crop Science, Madison, v. 13, p. 220-222, 1973.

EMBRAPA. Centro Nacional de Pesquisa de Solos (Rio de Janeiro, RJ). Sistema brasileiro de classificação de solos. Brasília: Embrapa-SPI/Embrapa-CNPS, 1999.412 p.

FEHR, W. R.; CAVINESS, C. E. Stages of soybean development. Ames: Iowa State University, 1977. 12 p.

FONTANELI, R. S.; SANTOS, H. P. dos; VOSS, M.; AMBROSI, I. Rendimento e nodulação de soja em diferentes rotações de espécies anuais de inverno sob plantio direto. Pesquisa Agropecuária Brasileira, Brasília, v. 35, n. 2, p. 349-355, fev. 2000.

FRANCO, A. A.; FONSECA, O. O.; MARRIEL, L. Efeito do nitrogênio mineral na atividade da nitrogenase e nitrato redutase durante o ciclo da soja no campo. Revista Brasileira de Ciência do Solo, Campinas, v. 2, p. 110-114, 1978.

GLIESSMAN, S. R. Agroecologia: processos ecológicos em agricultura sustentável. Porto Alegre: Editora da UFRGS, 2000. $653 \mathrm{p}$.

HANWAY, J. J.; WEBER, C. R. Dry matter accumulation in eight soybean (Glycine max (L.) Merrill) varieties. Agronomy Journal, Madison, v. 63, p. 227-230, 1971a.

HANWAY, J. J.; WEBER, C. R. Dry matter accumulation in soybean (Glycine max (L.) Merrill) plants as influenced by N, P and fertilization. Agronomy Journal, Madison, v. 63 , p. 263-266, 1971 b.

HENDERSON, J. B.; KAMPRATH, E. J. Nutrient and dry matter accumulation by soybeans. Raleigh: North Carolina State University, 1970. 27 p. (Agricultural Experiment Station Technical Bulletin, 197).

HUNGRIA, M.; VARGAS, M. A. T.; SUHET, A. R.; PERES, J. R. R. Fixação biológica de nitrogênio em soja. In: ARAÚJO, R. S.; HUNGRIA, M. (Ed.). Microrganismos de importância agrícola. Brasília: Embrapa-SPI, 1994. p. 9-89.

IBGE (Rio de Janeiro, RJ). Censo agropecuário 1995/ 1996. Rio de Janeiro, 1998. 231 p. (Censo Agropecuário, 24).
LEMPP, B.; MORAIS, M. G.; SOUZA, L. C. F. Produção de milho em cultivo exclusivo ou consorciado com soja e qualidade de suas silagens. Arquivo Brasileiro de Medicina Veterinária e Zootecnia, Belo Horizonte, v. 52, n. 3, p. 243-249, 2000.

OBEID, J. A.; ZAGO, C. P.; GOMIDE, J. A. Qualidade e valor nutritivo de silagem consorciada de milho (Zea mays, L.) com soja anual (Glycine max (L.) Merrill). Revista da Sociedade Brasileira de Zootecnia, Viçosa, MG, v. 14, p. 439-446, 1985.

OLIVEIRA, A. F. de; REZENDE, P. M. de; RAMALHO, M. A. P.; SILVA, A. P. de. Efeito da associação de cultivares de milho (Zea mays L.) e de soja (Glycine max (L.) Merrill) no rendimento e valor nutritivo da forragem. Ciência e Prática, Lavras, v. 12, n. 1, p. 66-77, 1988.

OLIVEIRA, F. L. Manejo orgânico da cultura do repolho (Brassica oleracea var. capitata): adubação orgânica, adubação verde e consorciação. 2001. 87 f. Tese (Mestrado em Fitotecnia) - Universidade Federal Rural do Rio de Janeiro, Seropédica, 2001.

PASCHOAL, A. D. Modelos sustentáveis de agricultura. Agricultura Sustentável, Jaguariúna, v. 2, n. 1, p. 11-16, 1995.

SANTOS, H. P. dos; LHAMBY, J. C. B.; WORETO, C. Efeito de culturas de inverno em plantio direto sobre a soja cultivada em rotação de culturas. Pesquisa Agropecuária Brasileira, Brasília, v. 33, n. 3, p. 289-295, mar. 1998.

SIQUEIRA, J. O.; FRANCO, A. A. Fixação biológica de nitrogênio. In:__. Biotecnologia do solo: fundamentos e perspectivas. Brasília: MEC/ABEAS/ESAL/FAEPE, 1988. p. 179-216.

SOUZA, F. A. Influência da adubação verde sobre o potencial de inóculo de fungos micorrízicos arbusculares e produção da mandioca (Manihot esculenta, Crantz). 1997. 88 f. Dissertação (Mestrado em Ciência do Solo) - Universidade Federal Rural do Rio de Janeiro, Seropédica, 1997.

VARGAS, M. A. T.; PERES, J. R. R.; SUHET, A. R. Adubação nitrogenada, inoculação e épocas de calagem para a soja em um solo sob cerrado. Pesquisa Agropecuária Brasileira, Brasília, v. 17, n. 8, p. 1127-1132, ago. 1982.

ZOTARELLI, L. Balanço de nitrogênio na rotação de culturas em sistema de plantio direto e convencional na região de Londrina-PR. 2000. 133 f. Dissertação (Mestrado em Ciência do Solo) - Universidade Federal Rural do Rio de Janeiro, Seropédica, 2000. 